\title{
The Level of Motives and Anxiety of Football Players among Different Ethnics in Malaysia
}

\author{
Vincent A. Parnabas ${ }^{1, *}$, Yahaya Mahamood ${ }^{2}$, Julinamary Parnabas $^{3}$ \\ ${ }^{1}$ Sport Science and Recreation Faculty, Universiti Teknologi MARA, Shah Alam, Selangor, Malaysia \\ ${ }^{2}$ Faculty of College of Art and Science, University Utara Malaysia (UUM), Malaysia \\ ${ }^{3}$ Institut Perguruan Malaysia, Kampus Darul Aman, Jitra, Kedah, Malaysia \\ *Corresponding Author: vincent@salam.uitm.edu.my
}

Copyright (C) 2013 Horizon Research Publishing All rights reserved.

\begin{abstract}
Previous research in Malaysia found that the six important motives, given by students-athletes for sport participation were achievement, body shape, physical fitness, teamwork, learning new skills and for challenges. However, research comparing different ethnic on taking part in sports, especially football is limited. The aim of this study is to find the motives of taking part in sport and level of anxiety among Malay, Chinese and Indians. A hundred and thirty student-athletes from different ethnic background were selected, to respond Purpose of Sport Questionnaire and Competitive State Anxiety Inventory -2 (CSAI-2). The sample was chosen from the Malaysian Sports Council, during Malaysian Inter-Schools Sports Competition. The result showed that the most highest motive for a Chinese ethnic taking part in football for physically active lifestyle, Malays ethnic for mastery or cooperation and Indians for social status or getting ahead. Furthermore, the result revealed that the football players in the categories of Indians ethnic exhibit higher level of competitive anxiety than categories of Malay and Chinese ethnic. Negative correlation noted between the level of motives and anxiety among all ethnics. Sports psychologists, coach or sport officers can use this research to develop appropriate football environment for Malays, Chinese and Indians, to maintain their interest in football.
\end{abstract}

Keywords Motives, Malay, Chinese, Indian, Football

\section{Background}

Motives can be defined as the intentions that cause a person to move, act, or to behave in a certain way (Brehm, 2004). Motives for participating in sports are many (Wann, 1997). Past studies, showed that the major motives student-athletes have for their participation are enjoying, for arousal, thrills and excitement, achievement, fitness, energy release, skill development, friendship, fun, and to become physically fit, healthy lifestyle (Bennett, Mousley,Kitchin \&
Ali-Choudhury, 2007; Devine \& Lepisto, 2005; White \& Duda, 1994; Gill, Gross \& Hudleston, 1983). Contary, anxiety as a negative emotion with a variety of cognitive, physiological and behavioural symptoms deteriorate sport performance (Weinberg \& Gould, 2010; Raglin \& Hanin, 2000; Martens, Vealey \& Burton, 1990). Anxiety has the tendency to threaten a person's well being because it increases a person's worries and doubt (Landers 1999). Therefore anxiety has the tendency to reduce the level of motives.

Anxiety consists of two sub-components namely cognitive and somatic anxiety, have the major effect on performance (Martens et al., 1990; Jarvis, 2002). The cognitive is the mental component, characterized by negative expectations about success or self-evaluation, negative self-talk, negative thoughts, fear of failure, loss of self-esteem, low self confidence, worries about performance, images of failure, inability to concentrate and disrupted attention (Ampofo-Boateng, 2009; Martens et al., 1990; Jarvis 2002). The somatic is the physiological element, activated the autonomic arousals, negative symptoms such as feelings of nervousness, difficulty of breathing, high blood pressure, dry throat, muscular tension, rapid heart rate, sweaty palms and butterflies in the stomach (Martens et al, 1990; Jones, 2000; Jarvis, 2002).

Social learning theory explains that people are motivated to take part in sports because they want to copy the skills of their sports heroes (Anderson \& South, 1993). Cognitive evaluation theory states that rewards can be divided into two types; controlling and informational. Controlling rewards, such as praise or trophies, are designed to influence (example, control) an individual's behaviour while informational rewards convey information about an individual's competence at a task. If a player believes her coach's praise is designed to control her behavior, the praise will lower her intrinsic motivation for the task. If, on the other hand, the player believes that the praise is designed to provide information about her successful performance, her intrinsic motivation for the task would increase (Wann, 1997).

There are many reasons why Malaysian athletes begin to 
participate in sports. For example, in a research study of 200 student-athletes from University Putra Malaysia, it was found that the six important motives, out of 30 motives, given by students for sport participation were achievement, body shape, physical fitness, teamwork, learning new skills and for challenges (Sim Poh Chuen, 1994). The same study also found that friendship and want to become popular are the lowest motive for sport participation among student-athletes at Universiti Putra Malaysia.

A variety of cultural comparative studies have been conducted in the field of sport psychology. Athletes from different cultural background show different motives for taking part in sport. Some progress has been made in addressing this problem in developed countries, especially comparing among blacks and whites but a similar research is yet to be conducted in Malaysia. Since lack of research in this area, there is still uncertain on motives of different cultural groups in Malaysia.

A number of researches have been conducted on motives for sports participation in developed countries (Wann, 1997), but, there is a lack of such research in developing countries, including Malaysia especially on different ethnics. Furthermore, research comparing different ethnic athletes directly are very limited. Comparing motives of different races on taking part in sports, especially on football players can bring a lot of new knowledge for cultural studies. Furthermore, most studies on motives in sport, done generally on sports without focusing on particular sports like football. The present research will evaluate the motives that encourage different background ethnics of football players to participate in sports. Three major ethics in Malaysia took part in this study; they are Malays, Chinese and Indians. Motives for taking part in sports include the following motives: Mastery or cooperation, physically active lifestyle, good citizen, competitiveness, high status career, enhance self-esteem and social status or getting ahead.

There is a need to plan and attract people to participate in football, but this will depend on their sport participation motives. Understanding the motives of those who are already involved as football players can help coaches, teachers and individuals to improve coaching, maintain motivation, prevent burn out and lower dropout rates in football. Lindner and Kerr (2001) argued that the motivation to participate in a sport was both complex and multifaceted. Different motives could determine participation decisions at various times and in desperate circumstances.

Knowing motives of different ethnics for participating in sports will help sports psychologists to develop an appropriate sports programme for those ethnics. In addition, identifying the range of motives given by different ethnic participants will help sports psychologists provide adequate and variety of football programmes to maintain interest among those ethnics. This is because understandings of why particular ethnic choose to take part in sports while others do not, could be of great practical value. In particular, government officials and sports psychologists in Malaysia need to conduct sports programmes to encourage different ethnics in Malaysia to take part in football could use the research findings.

A variety of cultural comparative studies have been conducted in the field of psychology. Athletes from different ethnic groups show different levels of cognitive and somatic anxiety in competition since lack of research in this area, this is still uncertain. Research has shown that ethnic identity to be associated with some psychological variables. Certain ethnic groups or cultural groups appear to be more prone to anxiety. Culture may be defined as the changing patterns of learning behaviour and the products of learning behaviour (including attitudes, values, knowledge and material objects) that are shared by and transmitted among members of society, it is an ongoing social heritage (Soyinka, 1991).

Until now, in Malaysia research on the levels of cognitive and somatic anxiety on different ethnic groups are rare. The anxiety level of somatic and cognitive on different ethnic groups in Malaysia, example, Malay, Chinese and Indian are still unknown. Different ethnic groups show different levels of anxiety since culture plays an important role (Montgomery \& Morris, 1994). Research, carried on Nepalese and Americans, showed that, cognitive anxiety on Nepalese are higher than Americans (Kohrt, Tol \& Harper, 2007). Cross cultural studies showed that Latin's have higher somatic anxiety than any other ethnic groups (Canino, 2004). Since none of Malaysian research focus on levels of anxiety on the different ethnic groups, especially on soccer sport, it's hard to predict the relationship of the level of anxiety and ethnics. Therefore this research can determine the level of anxiety between ethnic groups.

Malaysia consists of many ethnic groups with different cultural background, namely Malays, Chinese and Indians, maintain separate cultural identities (Kahn, 1998). According to Leonard (1998), there are two ways to classify races biologically : (a) a scheme based on observable physical characteristics (example skin colour, hair texture, eye shaped, lip thickness) called phenotypes, and (b) a scheme based on unobservable genetic features (example blood type) called genotypes.

In Malaysia, Malay is the largest ethnic, comprised 50.4\%, followed by Chinese, $23.7 \%$, indigenous $11 \%$, Indians $7.1 \%$, and others $7.8 \%$ (East Malaysia, especially Iban and Kadazan) (Malaysia Demographics Profile 2012). The religions in Malaysia are Muslim (or Islam - official) covered $60.4 \%$, followed by Buddhist $19.2 \%$, Christian $9.1 \%$, Hindu $6.3 \%$, Confucianism, Taoism, other traditional Chinese religions $2.6 \%$, other or unknown $1.5 \%$, none $0.8 \%$. Almost all the Malay ethnic are Muslims. The languages (which resemble ethnic background) are Bahasa Malaysia (official), English, Chinese (Cantonese, Mandarin, Hokkien, Hakka, Hainan, Foochow), Tamil, Telugu, Malayalam, Panjabi, Thai (Malaysia Demographics Profile 2012). Furthermore, in East Malaysia, exist several indigenous languages; widely spoken are Iban and Kadazan ethnic. Sometimes it's hard to believe that we remain in the same country, but their way of living differs dramatically from the other. 


\section{Objectives}

The aim of this study is to find the motives of taking part in sport and level of anxiety among Malay, Chinese and Indians. This research focus of football players, since football is considered as the most preferred sport among Malaysians. One of the most influential variables that involved of taking part in sports and anxiety is culture and belief. The Malays have a unique culture made up of customs, religion and belief that are different from other cultural groups in Malaysia (Salman, 1977). Thus, there is also a need for research to be carried out on the motives and level of anxiety of different ethnic group of Malaysians for taking part in sport, especially in football.

\section{Methodology}

The sample consisted of 130 football players, with Malay ethnic athletes $(\mathrm{N}=54)$, Chinese ethnic athletes $(\mathrm{N}=45)$ and Indian ethnic athletes $(\mathrm{N}=31)$. The sample was chosen from the Malaysian Sports Council, athletes who took part in Malaysian Inter-Schools Sports Competition. The questionnaires were distributed to student-athletes during the sport event. Participants' identify their racial group as 'Malay', Chinese' or 'Indians' in the demographic questionnaire.

A 46-item questionnaire called Purpose of Sport Questionnaire designed by Duda's (1989) was used. Students will indicate their responses to Duda's (1989) questionnaire on a Likert-typed scale ranging from strongly agree (5) and strongly disagree (1). Seven factors were derived from the questionnaire. They are Mastery or Cooperation, Physically Active lifestyle, Good Citizen, Competitiveness, High Status Career, Enhance Self-Esteem, and Social Status or Getting Ahead. Besides that, the 27-items of Competitive State Anxiety Inventory -2 (CSAI-2) was used in this study. It has three nine-item subscales measuring cognitive anxiety, somatic anxiety and self confidence.

\section{Results}

\subsection{Cronbach Reliability Coefficients}

In this study, Cronbach alpha were found ranging from .63 to .70 . In a similar study conducted by Duda, it was found that the Cronbach alpha coefficients were relatively high, ranging from .75 to .83 (Duda, 1989). Even though, some of the reliability were found to be lower than those in Duda's study (Duda, 1989) in the present study, they were still considered acceptable for analysis. In this study, coefficients of .70 and above were considered reliable, while those around .60 required some caution when the results were interpreted.

\subsection{Profile of the Respondents}

The profile of the respondents described the gender, age, marital status, level of participation in sports and courses. Table 1 shows the overall results of the respondents' profile of 69 males and 61 females.

The mean age for overall respondents was 22.08 years old (Table 1). The age of male varied from 18 to 27 years, where the mean age was 21.31 years old. The age of females ranged from the minimum of 18 to the maximum of 26 years old. The mean age for female respondents was 21.29 years old.

Table 1. Cronbach Reliability Coefficients

\begin{tabular}{|c|c|}
\hline Sport Participation Motives & Cronbach's Alpha (n=130) \\
\hline & .8211 \\
Mastery or Cooperation & .7810 \\
Physical Active Lifestyle & .7771 \\
Good Citizen & .7537 \\
Competitiveness & .7311 \\
High Status Career & .7121 \\
Enhance Self-Esteem & .6428 \\
Social Status or Getting Ahead & \\
\hline
\end{tabular}

The variable "level of participation in sport" is gathered through the studies. This variable is categorized into four levels. They are university, district, state and country levels. The result showed that one 37 respondents had participated at state level, whilst 28 respondents participate at district level, 40 had participated at university level, and 25 respondents participated at country level. The religion category showed that majority of the respondents, $70.00 \%$ were Muslims, whilst a size $13.08 \%$ Buddhism, $11.54 \%$ Christians and 5.38\% Hindus.

\subsection{Motives of Malay Ethnic Football Players}

The results showed that the motive of Malay ethnic respondents participated in sports were highest in Mastery or Cooperation $(m e a n=4.44)$, followed by Physically Active Lifestyle $($ mean $=3.96)$, Competitiveness $($ mean $=3.77)$, Enhance Self Esteem (mean= 3.06), Good Citizen (mean= 2.89), High Status Career (mean=2.78) and Social Status or Getting Ahead (mean= 2.61). The Malay respondents indicated Social Status as the lowest motive (Table 1).

\subsection{Motives of Chinese Ethnic Football Players}

The results showed that the motive of Chinese ethnic respondents participated in sports were highest in Physically Active Lifestyle (mean= 4.87), followed by Mastery or Cooperation $($ mean $=4.47)$, Competitiveness $($ mean $=3.51)$, High Status Career (mean=3.31), Social Status or Getting Ahead (mean= 2.57). Enhance Self Esteem (mean= 2.26) and Good Citizen (mean= 2.13), and The Chinese respondents indicated Good Citizen as the lowest motive (Table 2). 
Table 2. The Profile of Respondents $(n=130)$

\begin{tabular}{|c|c|c|c|c|}
\hline Variables & Frequency & Percentage & Mean & SD \\
\hline $\begin{array}{l}\text { Gender } \\
\text { Male } \\
\text { Female }\end{array}$ & & & & \\
\hline $\begin{array}{l}\text { Religion } \\
\text { Muslim } \\
\text { Buddhism } \\
\text { Christian } \\
\text { Hindu }\end{array}$ & $\begin{array}{l}69 \\
61\end{array}$ & $\begin{array}{l}53.08 \\
46.92\end{array}$ & & \\
\hline $\begin{array}{c}\text { Level of } \\
\text { Participation in } \\
\text { Sports } \\
\text { University }\end{array}$ & $\begin{array}{c}91 \\
17 \\
15 \\
7\end{array}$ & $\begin{array}{c}70.00 \\
13.08 \\
11.54 \\
5.38\end{array}$ & & \\
\hline District & 40 & 3077 & & \\
\hline State & 28 & $\begin{array}{l}30 . / 1 \\
21.54\end{array}$ & & \\
\hline National/Country & $\begin{array}{l}37 \\
25\end{array}$ & $\begin{array}{l}28.46 \\
19.23\end{array}$ & & \\
\hline $\begin{array}{l}\text { Malays } \\
\text { Chinese } \\
\text { Indians }\end{array}$ & $\begin{array}{l}54 \\
45 \\
31\end{array}$ & $\begin{array}{l}41.54 \\
34.61 \\
23.85\end{array}$ & & \\
\hline $\begin{array}{l}\text { Age } \\
\text { Overall } \\
\text { Male } \\
\text { Female }\end{array}$ & & & $\begin{array}{l}22.08 \\
21.31 \\
21.29\end{array}$ & $\begin{array}{l}1.78 \\
1.33 \\
1.38\end{array}$ \\
\hline
\end{tabular}

\subsection{Motives of Indian Ethnic Football Players}

The results showed that the motive of Indian ethnic respondents participated in sports were highest in Social Status or Getting Ahead (mean= 4.41), followed by Physically Active Lifestyle (mean $=4.27$ ), Mastery or Cooperation (mean= 4.07), Enhance Self Esteem (mean= 3.92), Good Citizen (mean= 3.71), High Status Career $($ mean $=3.13)$, and Competitiveness $($ mean $=2.07)$. The respondents indicated Social Status as the lowest motive (Table 3).

Table 3. Motives of Malay ethnic football players Participate in Sport $(n=54)$

\begin{tabular}{|ccc|}
\hline Motives & Mean & SD \\
\hline Mastery of Cooperation & 4.44 & 0.49 \\
Physically Active Lifestyle & 3.96 & 0.55 \\
Competitiveness & 3.77 & 0.59 \\
$\begin{array}{c}\text { Enhance Self Esteem } \\
\text { Good Citizen } \\
\text { High Status Career } \\
\text { Social Status or Getting } \\
\text { Ahead }\end{array}$ & 3.06 & 0.57 \\
\hline
\end{tabular}

Table 4. Motives of Chinese ethnic football players Participate in Sport $(\mathrm{n}=45)$

\begin{tabular}{|ccc|}
\hline Motives & Mean & SD \\
\hline Physically Active Lifestyle & 4.87 & 0.47 \\
Mastery of Cooperation & 4.47 & 0.44 \\
Competitiveness & 3.51 & 0.51 \\
High Status Career & 3.31 & 0.52 \\
Social Status or Getting Ahead & 2.57 & 0.57 \\
Enhance Self Esteem & 2.26 & 0.54 \\
Good Citizen & 2.13 & 0.58 \\
\hline
\end{tabular}

Table 5. Motives of Indian ethnic football players Participate in Sport $(\mathrm{n}=31)$

\begin{tabular}{|lll|}
\hline Motives & Mean & SD \\
Social Status or Getting Ahead & 4.41 & 0.35 \\
Physically Active Lifestyle & 4.27 & 0.34 \\
Mastery of Cooperation & 4.07 & 0.36 \\
Enhance Self Esteem & 3.92 & 0.41 \\
Good Citizen & 3.71 & 0.39 \\
High Status Career & 3.13 & 0.44 \\
Competitiveness & 2.07 & 0.54 \\
\hline
\end{tabular}

\subsection{Comparison of Ethnics}

Table 6 shows the F scores for the motives of taking part in football sport among the athletes of different ethnicity:

i. Mastery of Cooperation, $F(2,130)=4.001, p$ $=.05$.

ii. Physically Active, $\mathrm{F}((2,130)=4.017, \mathrm{p}=.05$.

iii. Competitiveness, $\mathrm{F}(2,130)=3.179, \mathrm{p}=.05$.

iv. High Status Career, F $(2,130)=3.181, \mathrm{p}=.05$.

v. Social Status or Getting Ahead, F $(2,130)=4.003$, $\mathrm{p}=.05$.

vi. Enhance Self Esteem, $F(2,130)=3.799, p=.05$.

vii. Good Citizen, $F(2,130)=3.332, p=.05$.

Table 6. Comparison of Motives of ethnic $(n=130)$

\begin{tabular}{|c|c|c|c|}
\hline Motives & Ethnic & Mean & F Value \\
\hline $\begin{array}{l}\text { Mastery of } \\
\text { Cooperation }\end{array}$ & $\begin{array}{l}\text { Malay } \\
\text { Chinese } \\
\text { Indian }\end{array}$ & $\begin{array}{l}4.44 \\
4.47 \\
4.07\end{array}$ & $4.001 *$ \\
\hline Physically Active & $\begin{array}{l}\text { Malay } \\
\text { Chinese } \\
\text { Indian }\end{array}$ & $\begin{array}{l}3.96 \\
4.87 \\
4.27\end{array}$ & $4.017 *$ \\
\hline Competitiveness & $\begin{array}{l}\text { Malay } \\
\text { Chinese } \\
\text { Indian }\end{array}$ & $\begin{array}{l}3.77 \\
3.51 \\
2.07 \\
\end{array}$ & $3.179^{*}$ \\
\hline High Status Career & $\begin{array}{l}\text { Malay } \\
\text { Chinese } \\
\text { Indian }\end{array}$ & $\begin{array}{l}2.78 \\
3.31 \\
3.13 \\
\end{array}$ & $3.181 *$ \\
\hline $\begin{array}{l}\text { Social Status or } \\
\text { Getting Ahead }\end{array}$ & $\begin{array}{l}\text { Malay } \\
\text { Chinese } \\
\text { Indian }\end{array}$ & $\begin{array}{l}2.61 \\
2.57 \\
4.41 \\
\end{array}$ & $4.003 *$ \\
\hline Enhance Self Esteem & $\begin{array}{l}\text { Malay } \\
\text { Chinese } \\
\text { Indian }\end{array}$ & $\begin{array}{l}3.06 \\
2.26 \\
3.92\end{array}$ & $3.799 *$ \\
\hline Good Citizen & $\begin{array}{l}\text { Malay } \\
\text { Chinese } \\
\text { Indian }\end{array}$ & $\begin{array}{l}2.89 \\
2.13 \\
3.71\end{array}$ & $3.332 *$ \\
\hline
\end{tabular}

$* \mathrm{p}<0.05$

Apparently, significant differences emerged for the 
athletes having different skills at competition except on the willingness to practice safe sex. Overall, the mean score obtained for the national level athletes was higher than those in other categories.

\subsection{Level of Competitive Anxiety}

One way ANOVA showed high significant differences of level of somatic competitive anxiety on categories of ethnics of football players, $F(3,130)=12.141, \mathrm{p}<.01$ (Table 7).

Table 7. Level of Competitive Anxiety based on ethnics of football players

\begin{tabular}{|c|c|c|c|}
\hline $\begin{array}{c}\text { Categories } \\
\text { According to } \\
\text { Ethnics football } \\
\text { players }\end{array}$ & Mean & Value- $F$ & Value- $p$ \\
\hline Malay & 12.1421 & \multirow{2}{*}{$12.141^{* *}$} & 0.000 \\
\hline Chinese & 10.1721 & & \\
\hline Indians & 15.4418 & & \\
\hline
\end{tabular}

$* * \mathrm{p}<0.01$

Post-Hoc Tukey Test (Table 8) showed that the level of competitive anxiety of Chinese ethnic football players was lower when made a comparison with Malay ethnic $(\mathrm{p}<0.05)$ and Indian ethnic $(p<0.05)$. Furthermore, the level of competitive anxiety on Indian ethnic football players was higher when made a comparison with Chinese ethnic $(p<0.05)$ and Malay ethnic $(p<0.05)$. In addition, the level of competitive anxiety of Malay ethnic football players was higher when made a comparison with Chinese ethnic $(p<0.05)$ but lower than Indian ethnicity $(p<0.05)$.

Table 8. Post Hoc Tukey: Level of Competitive Anxiety among Ethnic of football players

\begin{tabular}{|c|c|c|c|c|}
\hline $\begin{array}{c}\text { Categories } \\
\text { According to } \\
\text { Ethnic football } \\
\text { players }\end{array}$ & Malay & Chinese & Indians & $\mathrm{N}$ \\
\hline Malay & & $*(1.112)$ & $*(1.471)$ & 54 \\
\hline Chinese & & & $*(1.727)$ & 45 \\
\hline Indians & & & & 31 \\
\hline
\end{tabular}

$* \mathrm{p}<0.05$

\subsection{Level of Motives and Competitive Anxiety}

Negative correlation coefficient (Table 9) was noted between level of motives and competitive anxiety of Malay $(\mathrm{r}=-.011, \mathrm{p}<.01)$, Chinese $(\mathrm{r}=-.037, \mathrm{p}<.01)$ and Indians $(\mathrm{r}=-.051, \mathrm{p}<.01)$.

Table 9. The Relationship between level of motives and Competitive Anxiety among Athletes of different ethnics

\begin{tabular}{|c|c|}
\hline $\begin{array}{c}\text { Categories According to } \\
\text { Ethnics football players }\end{array}$ & $\begin{array}{c}\text { Level of Motives and Competitive } \\
\text { Anxiety }\end{array}$ \\
\hline Malay & $-0.011^{* *}(0.000)$ \\
\hline Chinese & $-0.037^{* *}(0.000)$ \\
\hline Indians & $-0.051^{* *}(0.000)$ \\
\hline
\end{tabular}

$* * \mathrm{p}<.01$

\section{Discussions}

\subsection{Motives of Malay ethnic football players}

The results showed that the motive of Malay ethnic respondents participated in football were highest in Mastery or Cooperation. According to the competence motivation theory people engage in sports as a means of mastering their surroundings (Cox, 2011). This is achieved through the learning of sports-skills (Anshel, 2011). The successful mastery of sport skills results in the experiencing of pleasant emotions and increased self-confidence. Furthermore, successful attempts for Malays at mastery, promote self-efficacy and feeling of personal competence, which in turn fosters high competence motivation. Cooperation in football teams involves Malays to fulfill their desire to raise the performance of all as a team experience; cares for others, empathizes, congratulates others; looks forward to the next contest as an opportunity to partake in a competition.

According to the competence motivation theory people engage in sports as a means of mastering their surroundings (Cox, 2011). This is achieved through the learning of sports-skills (Anshel, 2011; Harter, 1981). The successful mastery of sport skills results in the experiencing of pleasant emotions and increased self-confidence (Harter, 1981). Furthermore, these pleasant feelings will serve Malay athletes as an incentive to continue to take part in sports. In other words, successful attempts at mastery promote self-efficacy and feeling of personal competence, which in turn fosters high competence motivation for Malay athletes. As competence motivation increases, the Malay athletes is encouraged to make further mastery attempts (Cox, 2011).

\subsection{Motives of Chinese ethnic football players}

The results showed that the motive of Chinese ethnic respondents participated in football were highest in Physically Active Lifestyle. Physically active lifestyle is the motive to take part in sports for physical reasons, notably health, weight, or keeping fit (Kilpatrick, Hebert \& Bartholomew 2005; Wann, 1997). Taking part in physical activity are important to reduce the risk of coronary heart disease, cancers, obesity and many other health related problems (Adair, 2008; Allender, Cowburn, Foster, 2006). Taking part in football can increase the level of physical activity, as an ideal way to reduce health problems. Taking part in football as a physically active lifestyle enhances the fitness level, improves the immune system, mental health, maintaining healthy bones, reducing health problems, and increases the effective functioning of the body organ.

Study done by Ro and Hyun (2012) showed that body shape satisfaction was significantly higher in Chinese ethnic compared to Korean. In Malaysia, Chinese look much fitter in their body shape compared to other races.

\subsection{Motives of Indian Ethnic Football Players}


The results showed that the motive of Indian ethnic respondents participated in football were highest in Social Status or Getting Ahead. A social motive is an interest in people and the ways a person prefers to relate to other people (Wann, 1997). Study of Wang, Myers and Yanes (2010), and Sabiston and Crocker (2008) found that the interaction among their colleagues encourages people to participate in sports. Indian, as a minority ethnic in Malaysia has a strong desire to be with others and to function as members of a team. For Indians, the social aspects of football are an important reason for their participation. Indians found their motivation to take part in football was derive from something relating to a social motive, like to enjoy camaraderie and to mix socially with others who enjoy the same activity as a team. Social reasons for taking part in football range from meeting new people to deal with loneliness and social isolation. Research of Henderson and Ainsworth (2001) showed that social support was the most important motives of African-American and American Indian women choosing to be active in sport.

\subsection{Level of Competitive Anxiety}

The result showed that the football players in the categories of Indians ethnic exhibit higher level of competitive anxiety than categories of Malay and Chinese ethnic. This might due to Indians culture. In Malaysia, no research has been done involving these four categories of ethnic, therefore the findings of the current research fail to make a comparison with the previous research. Most of the research on cross-cultural study has been carried out in the United States and Europe, but limited attention shown on the other part of the world (Lewis-Fernandez, Hinton, Laria, Patterson, Hofmann, Craske, Stein, Asnaani \& Liao, 2010).

The result of this research determined that certain symptoms of anxiety to "run together' in a particular culture. Research of Varela, Vernberg, Sanchez-Sosa, Riveros, Mitchell and Mashunkashey (2004) showed Mexican, Mexican American and European America, differed in their reporting of anxiety symptoms. This showed that significant cultural variations relates to anxiety. The present research was also supported by the research done by Kirkby and Liu (1999) that the Chinese athletes were reported to show lower scores on anxiety.

It is important to note that the Competitive State Anxiety Inventory -2 (CSAI-2), only measures the symptoms of anxiety, it cannot reveal what causes a person to feel the emotions. The other limitation of this study can be the different ethnic groups might interpret the questionnaire differently. The differences between the cultures of the ethnic groups may play an important role in interpretation of the items. Everything people see, touch, interact with and think is cultural (Nurlaila, Yuliar \& Gharaei, 2013). Therefore, it can be expected that respondents from the various ethnic groups will respond differently on the same items.

\subsection{Level of Motives and Competitive Anxiety}

The result showed that there exist negative correlation between the level of motives and anxiety among all ethnics. In other words, the higher the level of anxiety, the lower the level of motives. In sport, anxiety is manifest by negative expectations of success and subsequent negative self-evaluation that can prompt one or more of four types of negative mental consequences, including (a) worry and other negative thoughts, (b) images of disaster and other disturbing evaluation-related imagery, (c) concentration problems in which distractions prevent appropriate attention focus (d) control problems that vary from sight feelings of loss of control to feeling totally overwhelmed (Duda, 1998). Athletes can develop anxiety because of their inability to perform or fear of performance failure. Athletes also have the tendency to worry the negative evaluation of their schoolmate, teachers, friends, fans, which can cause the level of cognitive anxiety increase. Therefore, the level of anxiety has the tendency to affect the motives of taking part in sports.

\section{Recommendations}

This research showed that the motive of taking part in sport and level of anxiety among different ethnic groups is various. A Malay ethnic group taking part in sport for mastery or cooperation, Chinese for physically active lifestyle, while Indians for social status or getting ahead. Furthermore, the result revealed that the football players in the categories of Indians ethnic exhibit higher level of competitive anxiety than categories of Malay and Chinese ethnic. Negative correlation noted between the level of motives and anxiety among all ethnics.

Sports psychologists, coach or sport officers can use this research to develop appropriate football environment for Malays, Chinese and Indians, to maintain their interest in football. In addition, identifying the range of motives given by Malays, Chinese and Indians will help sports psychologists provide adequate and variety of football programmes regarding their motives in football.

Sport psychologists, sport counselors and coaches should train athletes to use coping strategies to reduce the level of anxiety, since the result of the research showed that the level of anxiety has the tendency to reduce the level of motives.

\section{REFERENCES}

[1] Adair, L. S. (2008). Child and adolescent obesity: Epidemiology and developmental perspectives. Physiology \& Behavior 94, 8-16.

[2] Allender, S., Cowburn, G., Foster, C. (2006). Understanding participation in sport and physical activity among children and adults: a review of qualitative studies. Health Educ. Res. $21,826-835$.

[3] Ampofo-Boateng, K. 2009. Understanding Sport Psychology. Selangor, Malaysia: UPENA. 
[4] Anderson, D., \& South, D. (1993). Racial differences in collegiate recruiting, retention and graduation rates. In $\mathrm{D}$. Brooks \& R. Althouse (Eds.), Athletics:TheAfrican-American athlete's experience (pp. 79-100). Morgantown, WV: Fitness Information Technology.

[5] Anshell, M.H. (2011). Sport Psychology from theory to practice. Scottsdale, Arizona: Gorsuch Scarisbrick.

[6] Bennett, R., Mousley, W., Kitchin, P. \& Ali-Choudhury, R. 2007. Motivations for participating in charity-affiliated sporting events. Journal of Customer Behaviour. 6(2), $155-178$.

[7] Brehm, B. A., (2004). Your role in the exercise adherence story. Successful fitness motivation strategies. Champaign, IL:Human Kinetics.

[8] Canino, G. 2004. Are Somatic Symptoms and Related Distress More Prevalent in Hispanic/Latino Youth? Some Methodological Considerations. Journal of Clinical Child \& Adolescent Psychology 33(2) :272 - 275.

[9] Cox, R. H. (2011). Sport Psychology: Concepts and Application. Dubuque: Brown \& Benchmark.

[10] Devine, R. \& Lepisto, L. (2005), Analysis of the Healthy Lifestyle Consumer, Journal of Consumer Marketing, 22 (5), 275-283.

[11] Duda, J.L.(1998). Advances in Sport and Exercise Psychology Measurement. Morgantown, USA: Fitness Information Technology.

[12] Duda, J.L. (1989). Relationship between Task and Ego orientation and the perceived purpose of sport among high school athletes. Journal of Sport and Exercise Psychology, 11(3), 318-335.

[13] Gill, D.L., Gross, J.B., \& Huddleston, S. (1983). Participation motivation in youth sports. International Journal of Sport Psychology, 14, 1-14.

[14] Harter, S. (1981). A model of intrinsic mastery motivation in children: Individual differences and developmental change. In A. Collins (Ed.), Minnesota symposium on child psychology (Vol. 14, pp. 215-255). Hillsdale, NJ: Erlbaum.

[15] Henderson, K., \& Ainsworth, B. (2001). Researching leisure and physical activity with women of color: Issues and emerging questions. Leisure Sciences, 23(1), 21-34.

[16] Jarvis, M. (2002). Sport Psychology. New York: Routledge.

[17] Jones, G. (2000). Stress and anxiety. In S.J. Bull, Sport Psychology: A self-help Guide. Ramsbury, Marlborough: Crowood.

[18] Kahn, J. S. 1998. Southeast Asian Identities: Culture and the Politics of Representation in Indonesia, Malaysian, Singapore and Thailand. Singapore: Institute of Southeast Asian Studies.

[19] Kilpatrick, M., Hebert, E., \& Bartholomew, J. (2005) College students' motivation for physical activity: Differentiating men's and women's motives for sport participation and exercise. J Am College Health, 54, 87-94.

[20] Kirkby R.J \& Liu J. (1999). Precompetition anxiety in Chinese athletes. Percept Mot Skills, 88(1):297-303.

[21] Kohrt, B.A., Tol, W.A. \& Harper, I. 2007. Reconsidering somatic presentation of generalized anxiety disorder in Nepal.
Journal of Nervous and Mental Disease 6: 544.

[22] Leonard, W.M. 1998. A Sociological Perspective of Sport. London: Allyn and Bacon.

[23] Lewis-Fernández, R, Hinton DE, Laria A.J, Patterson EH, Hofmann S.G, Craske M.G, Stein D.J, Asnaani A, Liao B. (2010). Culture and the anxiety disorders: recommendations for DSM-V. Depression and anxiety. 27(2):212-29.

[24] Lindner, K. \& Kerr, J. (2001), Predictability of Sport Participation Motivation from Metamotivational Dominances and Orientations. Personality and Individual Differences, Vol. 30(6), 759-773.

[25] Malaysia Demographics Profile 2012.(http://www.indexmun di.com/malaysia/demographics_profile.html).

[26] Martens, R., Vealey, R.S., \& Burton, D. (1990). Competitive Anxiety in Sport. Champaign, Illinois: Human Kinetics.

[27] Montgomery, B., \& Morris, L. 1994. Living with anxiety. Singapore: Heinemann Asia.

[28] Nurlaila, I., Yuliar, S. \& Gharaei, R. A. 2013. Multiculturality in Indonesia's Biofuel Innovation Initiative: Critical Issues. Journal of ASIAN Behavioral Studies, 3(8), 79-88.

[29] Sabiston \& Crocker. (2008). Exploring self-perceptions and social influences as correlates of adolescent leisure-time physical activity. Journal of Sport \& Exercise Psychology, 30 (1), 33-22.

[30] Sim Poh Chuen. (1994). Motif penglibatan atlit Universiti Putra Malaysia dalam kegiatan sukan. Unpublished degree's thesis. Universiti Putra Malaysia, Serdang, Malaysia.

[31] Soyinka, W. (1991). Africa's Cultural Producers. Society, 28, $32-40$.

[32] Raglin, J.S. \& Hanin, Y.L. (2000). Competitive anxiety. In Yuri, L.H., Emotions in Sport. Champaign, IL: Human Kinetics.

[33] Ro, Y \& Hyun, W. 2012. Comparative study on body shape satisfaction and body weight control between Korean and Chinese female high school students. Nutr Res Pract, 6(4), 334-339.

[34] Wang, L., Myers, D., \& Yanes, M. (2010). Creating student-centered learning experience through the assistance of high-end technology in physical education. Journal of Instructional Psychology, 37(4), 352-356.

[35] Wann, D.L. (1997). Sport Psychology. Upper Saddle River, New Jersey: Prentice-Hall.

[36] Weinberg, R.S. \& Gould, D.,(2010). Foundations of Sport and Exercise Psychology. Champaign, IL: Human Kinetics.

[37] White, S. A., \& Duda, L. D. (1994). The relationship of gender, level of sport involvement, and participation motivation to task and ego orientation. International Journal of Sport Psychology, 25(1), 4-18.

[38] Varela, R.E., Vernberg, E.M., Sanchez-Sosa, J.J, Riveros, A., Mitchell, M. \& Mashunkashey J. (2004). Anxiety reporting and culturally associated interpretation biases and cognitive schemas: a comparison of Mexican, Mexican American, and European American families. J Clin Child Adolesc Psychology, 33(2), 237-47 